\title{
HDL Particle Size and Its Association with Paraoxonase - 1 Activity in CAD Patients
}

\author{
${ }^{1}$ Dr. G. Komala, ${ }^{2}$ Fenitta Shirley .S, ${ }^{3}$ Dr. Lalitha. R, ${ }^{4}$ Mr. Padmanaban. S \\ ${ }^{1}$ The Dr. M.G.R. Medical University, Senior Assistant Professor, Department of Biochemistry, \\ Govt. Kilpauk Medical College, India \\ ${ }^{2}$ II MBBS student, The Dr. M.G.R. Medical University, Govt. Kilpauk Medical College, \\ India \\ ${ }^{3}$ The Dr. M.G.R. Medical University, Professor, Department of Biochemistry, \\ Govt. Kilpauk Medical College, India \\ ${ }^{4}$ Scientist B, NIRRH Field Unit, HRRC, ICMR.Govt. Kilpauk Medical College. \\ India.
}

\begin{abstract}
Newer insights into the pathogenesis of coronary artery disease reveals that maintaining normolipedemia therapeutically or by life style modifications does not attenuate the risk of CAD. Research reveals that in addition to concentration, qualitative parameters of lipoproteins needs attention. Small dense $L D L$ is more atherogenic and large HDL is no more functionally competent. HDL particle size captures key place as a novel diagnostic marker. This case-control study done on 50 CAD patients and 50 age and sex matched healthy individuals revealed that CAD patients had a higher mean HDL particle size and lower concentrations of Apo-Al and paraoxonase-1 activity, though the concentrations of HDL were significantly higher in cases due to statin therapy. Hence to assess risk in individuals consideration of HDL particle size along with lipid profile would be essential. It's cheap and cost effective by measuring apo-Al concentrations and deriving particle size by HDL/Apo-A1 ratio.
\end{abstract}

Keywords: HDL particle size; paraoxonase- 1 activity; apolipoprotein - Al; HDL/Apo-Al ratio; dyslipaedemia.

Abbreviations: CAD- Coronary artery disease, HDL-C - High density lipoprotein cholesterol , LDL- low density lipoprotein, PON -1 - paraoxonase-1 activity, Apo-A1 - apolipoprotein -A1,

\section{INTRODUCTION}

Coronary Artery Disease causes about two million deaths per year in India. CAD rates in urban India are now four-fold higher than in the United States. CAD rates are two to four times higher at all ages among Indians worldwide and five to ten times higher in those < 40 years of age [1].

One of the major risk factors of CAD is dyslipidaemia [2], which is routinely assessed by lipid profile. It is a well-known fact that HDL-C is cardio-protective. However, CAD occurs even in patients with normal HDL-C levels [3].

HDL, being the major storehouse of APO-A1, possesses an array of anti-inflammatory functions. Reverse Cholesterol Transport (RCT) is the major mechanism by which HDL prevents the formation of oxidized LDL [4].In addition, Apo-A1 inhibits the production of TNF- $\alpha$ and IL-1 $\beta$, thus preventing the activation of monocytes [5].

In CAD, Apo-A1 is replaced by Serum Amyloid A, an acute phase reactant. This leads to concomitant loss of Apo-A1 [6], and a decrease in the density of HDL, and an increase in the HDL particle size [7].

One of the anti-oxidative components of HDL is Paraoxonase-1, which is synthesized in the liver [8]. The various functions of PON1 are:

- Inhibition of LDL oxidation

- Inhibition of HDL peroxidation [9]. 
- Detoxification of Homocysteine thiolactone, a pro-atherogenic compound [10]

Serum PON-1 activity directly correlates with the amount of stearic acid and

dihomo-gamma- linolenic acid(DGLA) present in Apoprotein-A1 and phospholipids in HDL. These are saturated fatty acids. Any alteration in the fatty acid composition of HDL leads to a decrease in serum PON-1 activity [11].

Alteration of the fatty acid content of HDL leads to structural changes in the HDL molecule, including changes in its size and zeta potential. This leads to decreased paraoxonase-1 activity, by altering the phospholipid composition of HDL [11]. Loss of Apo-A1 content of HDL is the mainstay in the development of atherosclerosis with reference to HDL. Hence our attention has to shift towards determining the qualitative aspects of HDL in order to reduce the risk of CAD.

HDL size and composition vary among individuals and may be associated with cardiovascular disease and diabetes [12].

Since determination of HDL particle size by NMR spectroscopy does not prove cost effective, measurement of APO-A1 along with the routine lipid profile provides a simple way to determine the quality of the HDL particle. HDL-C/ApoA-I ratio could be a readily available biomarker for estimating HDL size [12].

Theoretically, a quasilinear increase in HDL size with HDL-C/APO-A1 ratio exists whereas experimentally determined results using NMR spectroscopy reveal HDL size increases proportionately with HDL-C/APO-A1 ratio [12]. The HDL particle size can be delineated from the formula:

HDL MEAN PARTICLE SIZE=4.66nm+12.31(HDL-C/APO-A1)

The purpose of our study is to determine the efficacy of HDL particle size as a diagnostic tool in $\mathrm{CAD}$, even in patients with normal HDL-C levels.

Therapeutic normalization of the quantity, quality and biological activities of HDL particles represents a novel approach to attenuating atherosclerosis in CAD.

The aim of the study is to determine the HDL particle size in CAD patients from the HDL-C/APO-A1 ratio and assess its correlation with PON1 activity.

\section{Materials AND Methods}

This case- control study conducted in the Departments of Biochemistry and Cardiology of Govt. Kilpauk Medical College, Chennai-10 comprised of 50 known cases of CAD and 50 healthy persons who were age and sex matched.

For the above case control study, sample size was calculated using the formula in open-epi software and the power of the study was obtained to be $90 \%$ with a confidence interval of $95 \%$. The number of subjects needed is 49 in each group.

The reference for the above was obtained by conducting a pilot study from which the mean HDL particle size in CAD patients was found to be $10.85 \mathrm{~nm}$ and in controls was found to be $9.12 \mathrm{~nm}$, resulting in a difference of $1.73 \mathrm{~nm}$ and a standard deviation of 3 . Using the formula from open-epi software, the sample size was found to be 49 in each group.

The exclusion criteria were known cases of hypothyroidism, alcoholics and smokers as these states were known to influence the parameters of the study.

The Institutional Ethics Committee of Govt. Kilpauk Medical College, Chennai-10, approved the study. $5 \mathrm{ml}$ of random venous sample was drawn from the antecubital vein under aseptic conditions after obtaining informed consent from all the study participants.

Serum was separated after centrifugation and aliquoted into eppendorfs to be stored in $-20{ }^{\circ} \mathrm{C}$ until further analysis. Biochemical analysis was performed in Autora -random access chemistry analyser with kits from Spinreact. HDL, LDL cholesterol levels (spinreact kits) \& Apo -A1 were assayed by direct methods using immunoturbidimetry principle ( biosystems kits). Serum PON- 1 activity was estimated spectrophotometrically using Paraoxon (0, 0-diethyl-0, 4- nitro phenyl phosphate) as the substrate for hydrolysis [13]. The absorbance was monitored at $405 \mathrm{~nm}$. One unit $(1 \mathrm{U})$ of PON activity was defined as 1 micromole of p-NP formed per minute per litre at 25 degree Celsius and the activity was expressed as U/L of serum. 
All biochemical analysis were performed after calibration with calibrators from Roche using level 1 and level 2 and assessed by controls from Bio-rad using both levels 1 and 3. PON activity was standardised and pooled sera was used for precision analysis.

Statistical analysis were performed using SPSS package version17. The results were computed with mean and $\mathrm{Sd}$ and $\mathrm{p}$ value of $<0.05$ was considered significant for $95 \%$ Confidence interval.

\section{RESUlts}

This case-control study revealed the mean age of cases to be 56.980 years and those of controls as 54.320 years $(\mathrm{p}=0.168)$. The percentage of males in cases and controls were $56 \%$ and females in cases and controls were $44 \%$, revealing that they are matched for age and sex.

Mean HDL particle size of cases was $10.168 \mathrm{~nm}$ which was higher than controls $(9.04 \mathrm{~nm}, \mathrm{p}=0.006)$. Mean Paraoxonase-1 activity was decreased in cases as compared to controls $(233.535 \mathrm{IU} / \mathrm{L}$ vs $336.015 \mathrm{IU} / \mathrm{L} \mathrm{p}=.017$ ). (Table No: 1 ). Apo lipoprotein A1 levels were lower in cases as compared to controls (113.248 mg/dl vs $116.418 \mathrm{mg} / \mathrm{dl})$.

The diagnostic performance of HDL particle size, or the accuracy of the same to discriminate diseased cases from normal cases is evaluated using Receiver Operating Characteristic (ROC) curve analysis .ROC of HDL particle size revealed that particle size $>9.554 \mathrm{~nm}$ was a strong predictor for development of CAD with a specificity of $92 \%$ and sensitivity of $80 \%$ Area under the curve was 0.933200 with $95 \%$ Confidence interval between 0.865175 to 0.973436 and Significance level P

(Area $=0.5)<0.0001$

Correlation of Apolipoprotein-A1 with Paraoxonase-1 activity revealed a positive correlation in cases with a $\mathrm{p}$ value of 0.007 .

The mean values of total cholesterol, triglycerides, LDL-C and VLDL-C were lower in cases $(206.9648 \mathrm{mg} / \mathrm{dl}, 161.7420 \mathrm{mg} / \mathrm{dl}, 94.5088 \mathrm{mg} / \mathrm{dl} \& 31.86 \mathrm{mg} / \mathrm{dl}$ respectively ) than controls $(237.105 \mathrm{mg} / \mathrm{dl}, 175.338 \mathrm{mg} / \mathrm{dl}, 120.532 \mathrm{mg} / \mathrm{dl} \& 34.580 \mathrm{mg} / \mathrm{dl}$ respectively ) while HDL-C $(50.2184 \mathrm{mg} / \mathrm{dl}$ vs $41.4374 \mathrm{mg} / \mathrm{dl}$ ) was higher in cases as against controls(Table No:2).

TableNo1. Parameters for Qualitative assessment of HDL

\begin{tabular}{|c|c|c|c|c|c|c|c|c|c|}
\hline & \multirow[t]{2}{*}{ Group } & \multirow[t]{2}{*}{$\mathrm{N}$} & \multirow[t]{2}{*}{ Mean } & \multirow[t]{2}{*}{$\begin{array}{c}\text { Std. } \\
\text { Deviation }\end{array}$} & \multirow[t]{2}{*}{$\begin{array}{c}\text { Std. Error } \\
\text { Mean }\end{array}$} & \multicolumn{2}{|c|}{$\begin{array}{c}\text { Levene's Test } \\
\text { for Equality of } \\
\text { Variances }\end{array}$} & \multicolumn{2}{|c|}{$\begin{array}{l}\text { t-test for } \\
\text { Equality of } \\
\text { Means }\end{array}$} \\
\hline & & & & & & $\mathrm{F}$ & Sig. & \begin{tabular}{l|l}
$\mathrm{T}$ \\
\end{tabular} & Df \\
\hline \multirow[t]{2}{*}{ Apolipoprotein-A1 ${ }^{\mathrm{a}}$} & CAD & 50 & 113.248 & 19.1549 & 2.7089 & 2.324 & .131 & -.995 & 98 \\
\hline & $\begin{array}{l}\text { NON } \\
\text { CAD }\end{array}$ & 50 & 116.418 & 11.8723 & 1.6790 & & & -.995 & 81.806 \\
\hline \multirow[t]{2}{*}{ HDL-C/APO-A1 Ratio } & CAD & 50 & .4433 & .05870 & .00830 & 7.653 & .007 & 8.997 & 98 \\
\hline & $\begin{array}{l}\text { NON } \\
\text { CAD }\end{array}$ & 50 & .3554 & .03642 & .00515 & & & 8.997 & 81.857 \\
\hline \multirow[t]{2}{*}{ HDL Particle Size $^{b}$} & CAD & 50 & 10.1681 & .70637 & .09990 & 7.945 & .006 & 9.532 & 98 \\
\hline & $\begin{array}{l}\text { NON } \\
\text { CAD }\end{array}$ & 50 & 9.0407 & .44794 & .06335 & & & 9.532 & 82.923 \\
\hline \multirow[t]{2}{*}{ Paraoxonase-1 Activity ${ }^{c}$} & CAD & 50 & 233.535 & 122.5009 & 17.3242 & 5.927 & .017 & -2.739 & 98 \\
\hline & $\begin{array}{l}\text { NON } \\
\text { CAD }\end{array}$ & 50 & 336.015 & 234.5215 & 33.1664 & & & -2.739 & 73.886 \\
\hline
\end{tabular}

Units $a=m g / d l, b=n m$ and $c=I U / L$

Picture No:1

\section{ROC curve}

\begin{tabular}{|l|l|}
\hline Variable & $\begin{array}{l}\text { HDL_PARTICLE_SIZE } \\
\text { HDLPARTICLE SIZE }\end{array}$ \\
\hline Classification variable & Group \\
\hline
\end{tabular}

\begin{tabular}{|l|r|c|}
\hline Sample size & & 100 \\
\hline Positive group : & Group = CAD & 50 \\
\hline Negative group : & Group = NON & 50 \\
& CAD & \\
\hline
\end{tabular}




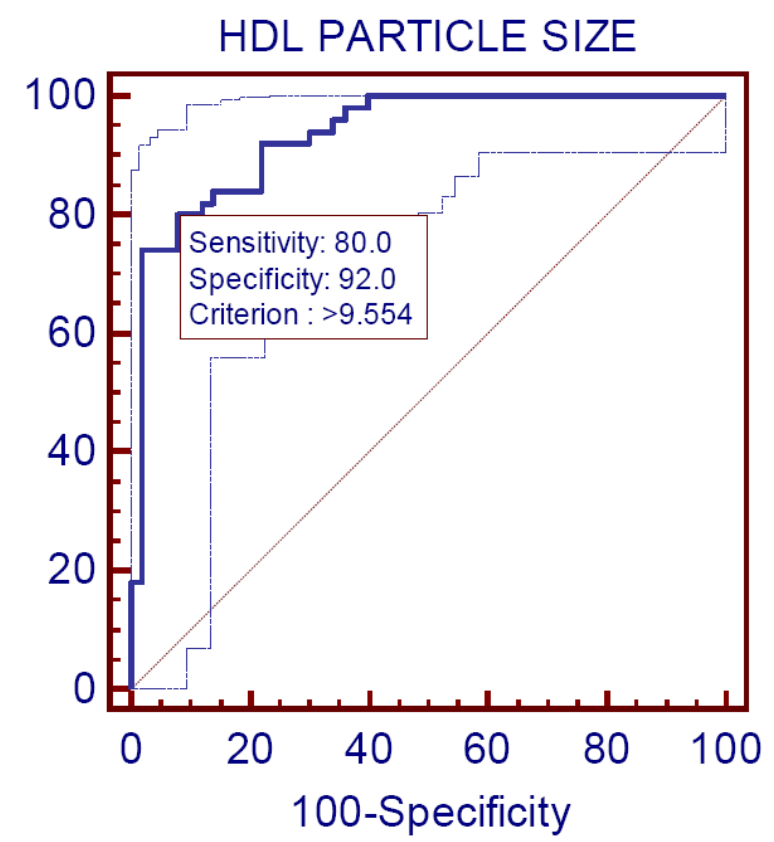

Area under the ROC curve (AUC)

\begin{tabular}{|l|c|}
\hline Area under the ROC curve (AUC) & 0.933200 \\
\hline Standard Error $^{\mathrm{a}}$ & 0.0242 \\
\hline 95\% Confidence interval & $\mathrm{b}$ \\
\hline Z statistic & 0.865175 to 0.973436 \\
\hline Significance level P (Area=0.5) & 17.890 \\
\hline
\end{tabular}

${ }^{\text {a }}$ Hanley \& McNeil, 1982

${ }^{\mathrm{b}}$ Binomial exact

Picture No: 2

Correlation of APOLIPOPROTEIN-A1 with PARAOXONASE-1 ACTIVITY

\begin{tabular}{|l|c|c|}
\hline & CASES & CONTROLS \\
\hline Pearson Correlation & .378 & -.136 \\
\hline $\mathrm{P}$ & .007 & .347 \\
\hline & & \\
\hline
\end{tabular}

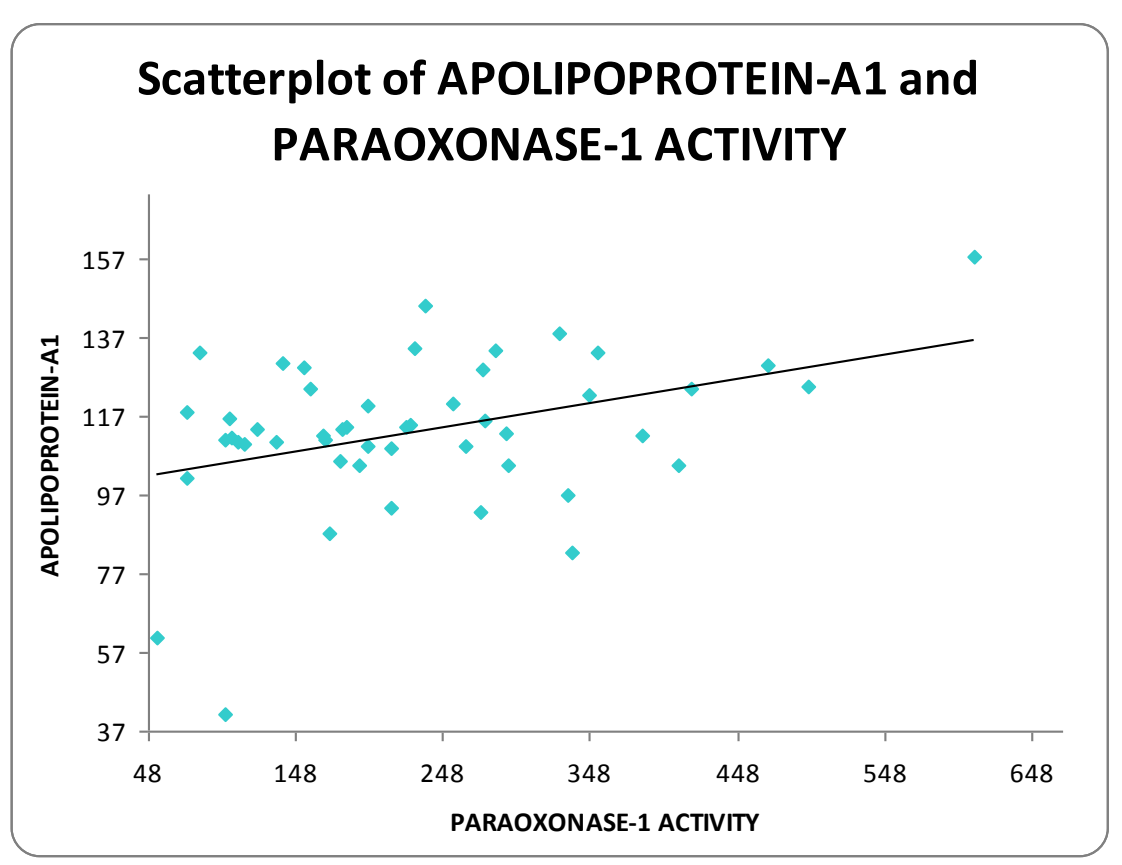


HDL Particle Size and Its Association with Paraoxonase- 1 Activity in CAD Patients

TableNo2. Lipid profile

\begin{tabular}{|c|c|c|c|c|c|c|c|c|c|}
\hline & \multirow[t]{2}{*}{ Group } & \multirow[t]{2}{*}{$\mathrm{N}$} & \multirow[t]{2}{*}{ Mean mg/dl } & \multirow[t]{2}{*}{$\begin{array}{c}\text { Std. } \\
\text { Deviation }\end{array}$} & \multirow[t]{2}{*}{$\begin{array}{l}\text { Std. Error } \\
\text { Mean }\end{array}$} & \multicolumn{2}{|c|}{$\begin{array}{c}\text { Levene's Test } \\
\text { for Equality } \\
\text { of Variances }\end{array}$} & \multicolumn{2}{|c|}{$\begin{array}{c}\text { t-test for } \\
\text { Equality of } \\
\text { Means }\end{array}$} \\
\hline & & & & & & $\mathrm{F}$ & Sig. & $\mathrm{t}$ & Df \\
\hline \multirow[t]{2}{*}{ Total Cholesterol } & CAD & 50 & 206.9648 & 50.932 & 40.63842 & 4.091 & .046 & -.998 & 98 \\
\hline & $\begin{array}{l}\text { NON } \\
\text { CAD }\end{array}$ & 50 & 237.105 & 34.629 & 47.02592 & & & -.998 & 49.006 \\
\hline \multirow[t]{2}{*}{ TGL } & CAD & 50 & 161.7420 & 60.66425 & 8.57922 & 1.649 & .202 & -1.011 & 98 \\
\hline & $\begin{array}{l}\text { NON } \\
\text { CAD }\end{array}$ & 50 & 175.3378 & 73.27942 & 10.36327 & & & -1.011 & 94.699 \\
\hline \multirow[t]{2}{*}{ HDL-C } & CAD & 50 & 50.2184 & 10.52392 & 1.48831 & 8.661 & .004 & 5.139 & 98 \\
\hline & $\begin{array}{l}\text { NON } \\
\text { CAD }\end{array}$ & 50 & 41.4374 & 5.93674 & .83958 & & & 5.139 & 77.319 \\
\hline \multirow[t]{2}{*}{ LDL-C } & CAD & 50 & 94.5088 & 21.64571 & 3.06117 & .047 & .828 & -5.833 & 98 \\
\hline & $\begin{array}{l}\mathrm{NON} \\
\mathrm{CAD} \\
\end{array}$ & 50 & 120.5315 & 22.94793 & 3.24533 & & & -5.833 & 97.667 \\
\hline \multirow[t]{2}{*}{ VLDL-C } & CAD & 50 & 31.86 & 12.149 & 1.718 & 1.739 & .190 & -1.008 & 98 \\
\hline & $\begin{array}{l}\text { NON } \\
\text { CAD }\end{array}$ & 50 & 34.58 & 14.714 & 2.081 & & & -1.008 & 94.612 \\
\hline
\end{tabular}

\section{DISCUSSION}

Globally, CAD is the leading cause of death and is predicted to remain so for the next 20 years [14]. The risk of CAD in Indians is 3-4 times higher than White Americans, 6-times higher than Chinese, and 20-times higher than Japanese $[15,16]$. Indians are prone as a community to CAD at a much younger age $[17,18]$. The prevalence of CAD is two-times higher $(10 \%)$ in urban than in rural India. South Indians have higher prevalence, $7 \%$ in rural and $14 \%$ in urban areas $[19,20]$.

In the present study the Total cholesterol and LDL-C values were found to be decreased in cases than in controls, whereas HDL-C levels were raised in cases as compared to controls.

This altered lipid profile in cases, is a consequence of statin therapy in CAD cases, as statins effectively lower the cholesterol and LDL levels. The various mechanisms by which statins exert their action is highlighted in the study, "The lipid and non-lipid effects of statins" by Wierzbicki AS et.al. [21].

According to the Framingham Heart Study, the risk of atherosclerotic disease is inversely related to blood levels of HDL-C. The lower the HDL-C levels, the greater the risk. The risk of CAD is increased by approximately $3 \%$ in women and $2 \%$ in men for each decrement of $1 \mathrm{mg} / \mathrm{dl}$ of HDL-C. HDL-C provides as an individual predictor of CAD, independent of LDL-C. Even in patients with normal LDL-C levels, low HDL-C can be of diagnostic value [22].

However, continuing debates exist as to whether the effects of statins on HDL-C are clinically beneficial. MJ Chapman has questioned the benefits of statins on HDL-C in his study-"Are the effects of statins on HDL-cholesterol clinically relevant?"

Moreover, it is still under contemplation whether very high levels of HDL-C is actually anti inflammatory [23].

The earliest study supporting this hypothesis was done by Van Lenten et.al. who reported that the acute phase response converted HDL from anti-inflammatory to proinflammatory. Hence even very high HDL-C levels can become deleterious to the patient. It is suggested that at very high levels, HDL can become a cholesterol donor instead of an acceptor. Hence the entire basis of the anti-oxidative capacity is lost and it becomes proatherogenic [23].

During an acute phase response, there is marked elevation in Serum Amyloid A (SAA) in HDL, which displaces Apo-A1 from its site. This leads to concomitant loss of Apo-A1. As Apo-A1 containing HDL exhibits the maximum LCAT activity, replacement by SAA inhibits LCAT activity and suppresses cholesterol efflux from peripheral cells.

SAA, in addition, enhances HDL binding to proteoglycans, promotes HDL immobilization in the arterial wall and accelerates its clearance from the circulation. 
Also, the levels of ceruloplasmin, another acute phase reactant, were found to be elevated in Acute Phase HDL (AP-HDL) than in normal HDL. Ceruloplasmin stimulates LDL-induced monocyte adhesion in the arterial wall, and renders HDL non-protective [24].

The study by Khovidhunkit et.al. describes the various changes taking place in the HDL particle in a setting of inflammation. When this inflammation is not able to repair the injury, persistent changes in the lipoprotein molecule occurs and the event turns towards chronicity. Hence the HDL lipid composition is severely altered in CAD [25].

As the original components of HDL are being reduced, the HDL triglyceride content keeps on increasing. The triglyceride-enriched HDL also impairs the cholesteryl ester delivery to hepatic cells, thus redirecting cholesterol to the macrophages.

The current study revealed reduced Apolipoprotein-A1 levels in cases as compared to controls, though not statistically significant. This accounts for the reduced anti-oxidative capacity of HDL in an inflammatory setting.

Apoprotein-A1 is the major protein determining the density as well as the helicity of HDL, as described by Thomas Ellis Grow in his paper titled 'Lipoprotein Structure: Apoprotein Interactions in Human Plasma High Density Lipoproteins'[25].

According to Hansel et.al. , the anti-oxidative activity is more potent in small, dense HDL-3 than large, light HDL-2. Decrease in the lipid content of HDL is thought to increase its capacity to remove cellular cholesterol; small, lipid-poor HDL particles thus represent more efficient cholesterol acceptors than their large, lipid-rich counterparts [26].

The HDL particle size was calculated using the HDL-C/Apo-A1 ratio and the particle size was found to be increased in cases as compared to controls. This can be correlated with the reduced Apo-A1 levels in CAD, which leads to an increase in HDL-C/APO-A1 ratio, and thereby an increase in HDL particle size.

A study by Scanu et.al. published as early as 1975 describes the inverse relationship between the size and density of lipoproteins [7]. Increase in triglyceride content as well as decrease in Apo-A1 leads to an increase in HDL mean particle size in CAD patients. Although this is contrary to many other studies which state that the HDL particle size decreases in CAD, the IDEAL and EPIC-NORFOLK studies were one of the first to state an increase in HDL particle size in CAD [27].

In CAD, there is a quantitative decrease in Apo-A1 content of HDL [24], in addition to a decrease in HDL-C. However, the decrease in Apo-A1 content is not proportionate to the decrease in HDL-C. Hence there is an increase in the HDL-C/APO-A1 ratio which leads to an increase in HDL particle size [22].

Increase in HDL particle size is associated with a decrease in the anti-oxidative capacity of HDL, which, in part, is mediated by paraoxonase- 1 .

Serum Paraoxonase-1 activity was assayed and it was found to be decreased in cases as compared to controls. This can be attributed to the reduced levels of Apo-A1, which contains an enormous amount of fatty acids.

A major part of the anti-oxidative effects of HDL is mediated by the enzyme Paraoxonase-1, a calcium-dependent esterase, synthesized in the liver. Presence of phospholipids and apoprotein-A1 is necessary for release of the enzyme from the liver. Hence, more than $95 \%$ of PON-1 synthesized is associated with HDL in the circulation [28].

Watson et.al.is the first to document an effect of Paraoxonase on oxidatively modified lipoproteins. PON1 has been demonstrated to destruct oxidized phospholipids in LDL, derived from arachidonic acid. Another major function of PON1 is inhibition of HDL oxidation by a peroxidase-like activity. Oxidative stress leads to an impairment of cholesterol efflux and RCT by HDL. Thus PON1 preserves the antiatherogenic activity of HDL [9].

PON1 confers protection from CAD by yet another mechanism, by causing degradation of Homocysteine Thiolactone, a pro-atherogenic compound. Hyperhomocysteinemia is an independent risk factor for CAD. Homocysteine thiolactone is the reactive anhydride of homocysteine that interacts with LDL, causing aggregation, increased density, and uptake by vascular macrophages to form foam cells. PON1 causes detoxification of Homocysteine Thiolactone in human blood, thereby reducing its proatherogenic effects [10]. 
It has been found that palmitic acid is the major fatty acid present in HDL. According to Boshtam et.al. , serum paraoxonase activity directly correlates with the amount of saturated fatty acids like stearic acid and dihomo-gamma-linolenic acid (DGLA) present in HDL [11].These fatty acids are present in the phospholipids and apolipoproteins found in HDL. A study by Razavi et.al. states that smaller HDL has a higher proportion of saturated fatty acids [29].Hence PON1 activity is more pronounced in small dense HDL rather than larger HDL particles.

Apoprotein-A1 is necessary for maintaining the normal helicity of HDL. Increase in HDL particle size is associated with loss of apoprotein-A1, which is made up of saturated fatty acids. Alteration of the fatty acid content of HDL leads to structural changes in the HDL molecule, including changes in its size and zeta potential. This leads to decreased paraoxonase- 1 activity, by altering the phospholipid composition of HDL [11].

Loss of Apo-A1 content of HDL is the mainstay in the development of atherosclerosis with reference to HDL. Hence our attention has to shift towards determining the qualitative aspects of HDL in order to reduce the risk of CAD.

As Apo-A1 is necessary for virtually every process involved in the release as well as functions of HDL, reduction in Apo-A1 level causes an array of dysfunctions in the functions of PON-1. It can either interfere with the release of PON-1 from liver or with the stability of the enzyme within the HDL particle. Apo-A1 is absolutely necessary for PON-1 activity, as described by Deakin et.al. in his study [28].

A positive correlation was found between Apo-A1 and Paraoxonase-1 activity in cases. This finding is in accordance with the fact that Apo-A1 is necessary for the normal functioning of PON-1.

An inverse relationship exists between HDL particle size and PON-1 activity through APO-A1. Thus apoprotein-A1 is the major crux around which the anti-inflammatory and anti-oxidative functions of HDL and PON-1 revolve.

Receiving Operating Characteristic (ROC ) curve of HDL particle size reaffirms the fact that particle size optimum cut off value $>9.554$ is a major predictor for development of CAD with a sensitivity of $80 \%$,Specificity $92 \%$ \&Area Under curve(AUC) is 0.9332 .This case controlled study, found an increase in HDL particle size and a reduction in PON-1 activity in CAD patients as compared to controls.

Therapy with statins must be re-considered since it has a wide array of side effects with limited benefits. Rather than looking towards normalizing the levels of HDL-C alone, our attention has to shift towards normalizing the qualitative aspects of $\mathrm{HDl}$, namely the HDL particle size.

Moreover, assessment of Apo-A1 along with the routine lipid profile provides a very cheap and easy tool to calculate the HDL particle size. By this way, the risk of CAD can be predicted even in persons with normal/very high HDL-C levels.

\section{Conclusion}

This study high lights the significance of HDL particle size in assessing its function, as anti-oxidant function is better with smaller HDL reinforced by PON-1 activity which is higher in smaller HDL as compared to larger HDL molecules. In patients with normal or high HDL levels, attention is to be drawn on the qualitative aspects of HDL like particle size and anti-oxidant function as assessed by PON -1 activity which can serve as better predicators of risk assessment rather the concentration of HDL alone.

\section{ACKNOWLEDGEMENT}

We gratefully acknowledge Indian Council of Medical Research for their part funding of Rs.10000 under the STS-2014 scheme for this research work. Grant Number 2014-03551 granted to Fenitta Shirley, II MBBS student.

Ethical approval: All procedures performed in studies involving human participants were in accordance with the ethical standards of the institutional and/or national research committee and with the 1964 Helsinki declaration and its later amendments or comparable ethical standards."

Informed consent: Informed consent was obtained from all individual participants included in the study. 


\section{REFERENCES}

[1] Enas EA. Coronary artery disease epidemic in Indians: a cause for alarm and call for action. Journal of the Indian Medical Association. 2000 Nov;98(11):694-5.

[2] Khot UN, Khot MB, Bajzer CT, Sapp SK, Ohman EM, Brener SJ, Ellis SG, Lincoff AM, Topol EJ. Prevalence of conventional risk factors in patients with coronary heart disease. Jama. 2003 Aug 20; 290(7):898-904..

[3] Cheung MC, Brown BG, Wolf AC, Albers JJ. Altered particle size distribution of apolipoprotein AI-containing lipoproteins in subjects with coronary artery disease. Journal of lipid research. 1991 Mar 1;32(3):383-94.

[4] Frank PG, Marcel YL. Apolipoprotein AI: structure-function relationships. Journal of lipid research. 2000 Jun 1;41(6):853-72.

[5] Hyka N, Dayer JM, Modoux C, Kohno T, Edwards CK, Roux-Lombard P, Burger D. Apolipoprotein AI inhibits the production of interleukin-1 $\beta$ and tumor necrosis factor- $\alpha$ by blocking contact-mediated activation of monocytes by T lymphocytes. Blood. 2001 Apr 15; 97(8):2381-9.

[6] Van Lenten BJ, Hama SY, De Beer FC, Stafforini DM, McIntyre TM, Prescott SM, La Du BN, Fogelman AM, Navab M. Anti-inflammatory HDL becomes pro-inflammatory during the acute phase response. Loss of protective effect of HDL against LDL oxidation in aortic wall cell cocultures. Journal of Clinical Investigation. 1995 Dec;96(6):2758.

[7] Scanu AM, Kruski AW. The chemistry of serum lipoproteins. Pharmacology of lipid transport and atherosclerotic processes. International encyclopedia of pharmacology and therapeutics, section. 1975; 24:21-38.

[8] Garin MC, Moren X, James RW. Paraoxonase-1 and serum concentrations of HDL-cholesterol and apoA-I. Journal of lipid research. 2006 Mar 1;47(3):515-20.

[9] Aviram M, Rosenblat M, Bisgaier CL, Newton RS, Primo-Parmo SL, La Du BN. Paraoxonase inhibits high-density lipoprotein oxidation and preserves its functions. A possible peroxidative role for paraoxonase. Journal of Clinical Investigation. 1998 Apr 15;101(8):1581.

[10] Yilmaz N. Relationship between paraoxonase and homocysteine: crossroads of oxidative diseases. Arch Med Sci. 2012 Feb 29; 8(1):138-53.

[11] Boshtam M, Emami Razavi A, Pourfarzam M, Ani M, Naderi G, Basati G et al. Serum Paraoxonase 1 Activity Is Associated with Fatty Acid Composition of High Density Lipoprotein. Disease Markers. 2013; 35:273-280.

[12] Mazer NA, Giulianini F, Paynter NP, Jordan P, Mora S. A comparison of the theoretical relationship between HDL size and the ratio of HDL cholesterol to apolipoprotein AI with experimental results from the Women's Health Study. Clinical chemistry. 2013 Jun 1; 59(6):94958.

[13] Eckerson HW, Wyte CM, La Du BN. The human serum paraoxonase/arylesterase polymorphism. American journal of human genetics. 1983 Nov;35(6):1126.

[14] Mathers CD, Loncar D. Projections of global mortality and burden of disease from 2002 to 2030. Plos med. 2006 Nov 28;3(11):e442.

[15] Enas EA, Garg A, Davidson MA, Nair VM, Huet BA, Yusuf S. Coronary heart disease and its risk factors in first-generation immigrant Asian Indians to the United States of America. Indian heart journal. 1995 Dec; 48(4):343-53.

[16] Enas EA. High rates of CAD in Asian Indians in the United States despite intense modification of lifestyle: what next. Curr Sci. 1998 Jun 25;74(12):1081-6.

[17] Janus ED, Postiglione A, Singh RB, Lewis B. The modernization of Asia implications for coronary heart disease. Circulation. 1996 Dec 1; 94(11):2671-3.

[18] McKeigue PM, Ferrie JE, Pierpoint T, Marmot MG. Association of early-onset coronary heart disease in South Asian men with glucose intolerance and hyperinsulinemia. Circulation. 1993 Jan 1; 87(1):152-61.

[19] DeStefano F, Merritt RK, Anda RF, Casper ML, Eaker ED. Trends in nonfatal coronary heart disease in the United States, 1980 through 1989. Archives of internal medicine. 1993 Nov 8; 153(21):2489-94. 
[20] Bhatia ML. Prevalence of coronary heart disease in India: a contemporary view. Indian heart journal. 1994 Dec;47(4):339-42.

[21] Wierzbicki AS, Poston R, Ferro A. The lipid and non-lipid effects of statins. Pharmacology \& therapeutics. 2003 Jul 31; 99(1):95-112.

[22] Wilson PW, Abbott RD, Castelli WP. High density lipoprotein cholesterol and mortality. The Framingham Heart Study. Arteriosclerosis, Thrombosis, and Vascular Biology. 1988 Nov 1;8(6):737-41.

[23] Navab M, Anantharamaiah GM, Reddy ST, Van Lenten BJ, Ansell BJ, Fogelman AM. Mechanisms of disease: proatherogenic HDL-an evolving field. Nature Reviews Endocrinology. 2006 Sep 1;2(9):504-11.

[24] Van Lenten BJ, Hama SY, De Beer FC, Stafforini DM, McIntyre TM, Prescott SM, La Du BN, Fogelman AM, Navab M. Anti-inflammatory HDL becomes pro-inflammatory during the acute phase response. Loss of protective effect of HDL against LDL oxidation in aortic wall cell cocultures. Journal of Clinical Investigation. 1995 Dec;96(6):2758.

[25] Khovidhunkit W, Kim MS, Memon RA, Shigenaga JK, Moser AH, Feingold KR, Grunfeld C. Effects of infection and inflammation on lipid and lipoprotein metabolism: mechanisms and consequences to the host. The Journal of Lipid Research. 2004 Apr; 45(7):1169-96.

[26] Kontush A, Chapman MJ. Antiatherogenic small, dense HDL - guardian angel of the arterial wall?. Nature clinical practice Cardiovascular medicine. 2006 Mar 1;3(3):144-53.

[27] van der Steeg WA, Holme I, Boekholdt SM, Larsen ML, Lindahl C, Stroes ES, Tikkanen MJ, Wareham NJ, Faergeman O, Olsson AG, Pedersen TR. HDL cholesterol, HDL particle size and apolipoprotein AI: significance for cardiovascular disease risk. Improving Cardiovascular Disease Prevention: from Risk Assessment to Novel Therapy. 2009; 51(6):29.

[28] Deakin S, Leviev I, Gomaraschi M, Calabresi L, Franceschini G, James RW. Enzymatically active paraoxonase-1 is located at the external membrane of producing cells and released by a high affinity, saturable, desorption mechanism. Journal of Biological Chemistry. 2002 Feb 8; 277(6):4301-8.

[29] Razavi AE, Pourfarzam M, Ani M, Naderi GA. The associations between high-density lipoprotein mean particle size and its fatty acid composition. Biomarkers. 2013 Apr 3;7(2):23545. 


\section{AUTHORS' BIOGRAPHY}

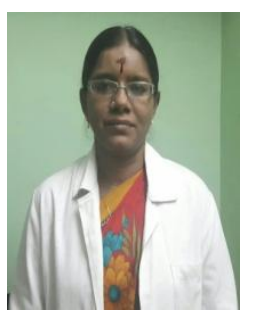

DR. G. KOMALA MD, is Interested in teaching and motivating students not only in academics but also in Research. Has experience in guiding undergraduates and postgraduates in research. Till dates have guided 65 research concepts by students in Government Kilpauk Medical College.

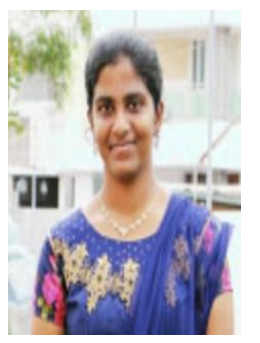

S. Fenitta Shirley, is Undergraduate at Government Kilpauk Medical College, Chennai

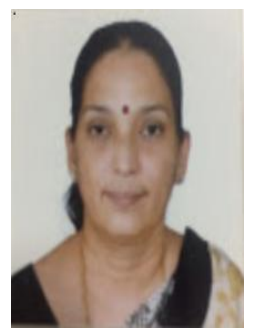

Dr. R. Lalitha, is M.D. Biochemistry from Madras Medical college, and subsequently worked in almost all the medical colleges in Tamil Nadu. Had been a guide to post graduates for more than nine years for their research work. Some of those works were published in journals like Indian journal of medical biochemistry, journal of medical sciences and health etc.

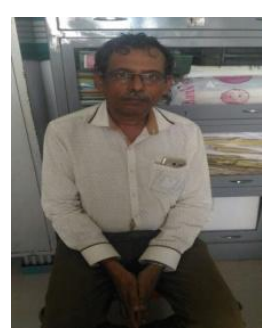

\section{S. Padmanaban}

M.Sc Statistics - Loyola College,

Pursuing P.hD in statistics from Loyola college

Successfully completed P.hD provisional and going to submit Synopsis soon

Research Scientist B Non Medical- HRRC, ICMR, since 09.07.1987.

Co-Investigator for UGC Minor Research Project.

Having 15 publications author or co author. 